\title{
TRAIL/NF-KB/CX3CL1 Mediated Onco-Immuno Crosstalk Leading to TRAIL Resistance of Pancreatic Cancer Cell Lines
}

\author{
Claudia Geismann ${ }^{1}$, Wiebke Erhart ${ }^{1}$, Frauke Grohmann ${ }^{1}$, Stefan Schreiber ${ }^{1,2}$, \\ Günter Schneider ${ }^{3}$, Heiner Schäfer ${ }^{1,4}$ and Alexander Arlt 1,* (iD \\ 1 Laboratory of Molecular Gastroenterology \& Hepatology, Department of Internal Medicine I, \\ UKSH-Campus Kiel, 24105 Kiel, Germany; cgeismann@email.uni-kiel.de (C.G.); \\ wiebke.erhart@uksh.de (W.E.); fraukethun@gmx.de (F.G.); s.schreiber@mucosa.de (S.S.); \\ hschaef@1med.uni-kiel.de (H.S.) \\ 2 Institute of Clinical Molecular Biology, UKSH Campus Kiel, 24105 Kiel, Germany \\ 3 Technische Universität München, Klinikum Rechts der Isar, II. Medizinische Klinik, 81675 Munich, \\ Germany; guenter.schneider@tum.de \\ 4 Institute of Experimental Cancer Research, UKSH Campus Kiel, 24105 Kiel, Germany \\ * Correspondence: aarlt@1med.uni-kiel.de; Tel.: +49-431-5002-2210
}

Received: 4 May 2018; Accepted: 4 June 2018; Published: 4 June 2018

\begin{abstract}
Pancreatic ductal adenocarcinoma (PDAC) is one of the most lethal malignant neoplasms and registers rising death rates in western countries. Due to its late detection in advanced stages, its extremely aggressive nature and the minimal effectiveness of currently available therapies, PDAC is a challenging problem in the clinical field. One characteristic of PDAC is a distinct desmoplasia consisting of fibroblasts, endothelial and immune cells as well as non-cellular components, contributing to therapy resistance. It is well established that the NF- $\mathrm{KB}$ signaling pathway controls inflammation, cancer progression and apoptosis resistance in PDAC. This study attempts to identify NF- $\mathrm{KB}$ target genes mediating therapy resistance of humane PDAC cell lines towards death ligand induced apoptosis. By using a genome wide unbiased approach the chemokine CX3CL1 was established as a central NF-KB target gene mediating therapy resistance. While no direct impact of CX3CL1 expression on cancer cell apoptosis was identified in co-culture assays it became apparent that CX3CL1 is acting in a paracrine fashion, leading to an increased recruitment of inflammatory cells. These inflammatory cells in turn mediate apoptosis resistance of PDAC cells. Therefore, our data dissect a bifunctional cross-signaling pathway in PDAC between tumor and immune cells giving rise to therapy resistance.
\end{abstract}

Keywords: apoptosis resistance; TRAIL; pancreatic cancer; NF-kB; CX3CL1

\section{Introduction}

Pancreatic ductal adenocarcinoma (PDAC) is the fourth leading cause of cancer related death in Western countries. Poor therapy efficiency due to late diagnostic capabilities and a fast developing chemoresistance is reflected in rising death rates and makes PDAC to a challenging problem in the biomedical and clinical field [1].

Inflammation plays a crucial role in initiation and progression of PDAC. Together with a pronounced desmoplastic reaction, consisting of fibroblasts, immune and endothelial cells as well as extracellular matrix proteins inflammatory reactions represent a characteristic hallmark of PDAC [2,3]. Recently, the interaction of attracted immune cells with cancer cells gained particular attention because cytokines secreted by immune cells seem to promote the initiation, propagation and metastasis of 
tumors [4]. Beyond that, a continuously increasing body of evidence shows that in addition to the desmoplastic cells also the cancer cells express a variety of cytokines to create a tumor-promoting microenvironment. Thus, pancreatic cancer cells secrete for instance IL-13 to stimulate tumor promoting macrophages [5] or the chemokine CCL20 which facilitates the attraction of immune cells providing resistance against death receptor ligand mediated apoptosis [6]. In addition, a third modality of cytokine mediated tumor promotion, cancer cells express cytokine receptors and foster via the binding of the corresponding ligand an autocrine signaling loop which promotes cancer cell growth [4].

Because of the poor efficacy of conventional chemotherapeutic drug regimens, death receptor ligands are under investigation for PDAC treatment. Initially, the TNF alpha related apoptosis inducing ligand (TRAIL) was shown to be a quite promising and effective anti-cancer agent, which induced in cancer cells an extrinsic apoptotic response while sparing most normal cells. However, subsequent studies, demonstrated a robust resistance in a multitude of cancer cells against TRAIL induced apoptosis, among them pancreatic cancer cell lines [7-9]. This resistance could be attributed on one hand to constitutively upregulated anti-apoptotic proteins like c-FLIP, Bcl-XL and XIAP [10] and on the other hand to apoptosis inhibiting signaling pathways like protein kinase (pK)-c or NF-kB [8]. In line with this, an enhanced NF- $\mathrm{kB}$ activation correlates with TRAIL resistance in colorectal or pancreatic cancer cell lines [11,12].

The NF- $\kappa B$ transcription factor family consists of five subunits, NF- $k B 1$ (also called p50), NF-кB2 (also called p52), RelA (also called p65), RelB and c-Rel. While all subunits bear a Rel homology domain (RHD) to form heterodimers only RelA, RelB and c-Rel harbor a transactivation domain (TAD) to bind cognate DNA elements and activate target genes [13-15]. Until now, the NF- $\mathrm{KB}$ target genes that convey chemoresistance in PDAC either through death receptor signaling or in association with chemotherapeutic drugs, are rarely investigated. Some studies propose a crosstalk with other transcription factors (STAT3) and the classical inhibitors of apoptosis (c-FLIP, cIAP) are supposed to be involved [16-19], too.

Given the fact that the inducible but not constitutive NF- $\kappa B$ activity prevents death receptor mediated signaling in PDAC cells [14], the present study aimed to identify RelA target genes jointly responsible for TRAIL mediated apoptosis resistance in pancreatic cancer cells. Thus, we identified the cytokine CX3CL1 as a direct NF- $\mathrm{KB}$ (RelA) target gene, which attracts immune cells to the site of tumor and thereby modulating the resistance of the cancer cells through a paracrine signaling pathway.

\section{Results}

\subsection{Chemokine CX3CL1 is a RelA Target Gene}

It is well established that an elevated NF- $\mathrm{KB}$ activity is associated with an augmented resistance against chemotherapy-induced apoptosis in pancreatic cancer $[6,7,20]$. To identify genes, responsible for the resistance towards TRAIL mediated apoptosis, genome wide transcriptome analysis with TRAIL resistant (Panc1) and sensitive (Miapaca2) PDAC cell lines were performed (series accession: GSE87287; http:/ / www.ncbi.nlm.nih.gov/geo/query/acc.cgi?acc=GSE87287). In a second transcriptome analysis resistant Panc1 cells were first treated with specific siRNA towards the most abundant NF- $\mathrm{KB}$ subunit RelA or control siRNA and then treated with TRAIL to identify RelA dependent TRAIL target genes. Combining the results from both analysis, we were able to identify specific RelA target genes and candidates downstream thereof mediating the resistant phenotype (Figure 1A). Western blotting confirmed an effective reduction of the RelA subunit in untreated and $5 \mathrm{~h}$ TRAIL PDAC cells (Figure 1B). As expected, we observed no relevant change in protein levels of RelA through the TRAIL treatment alone. 
A

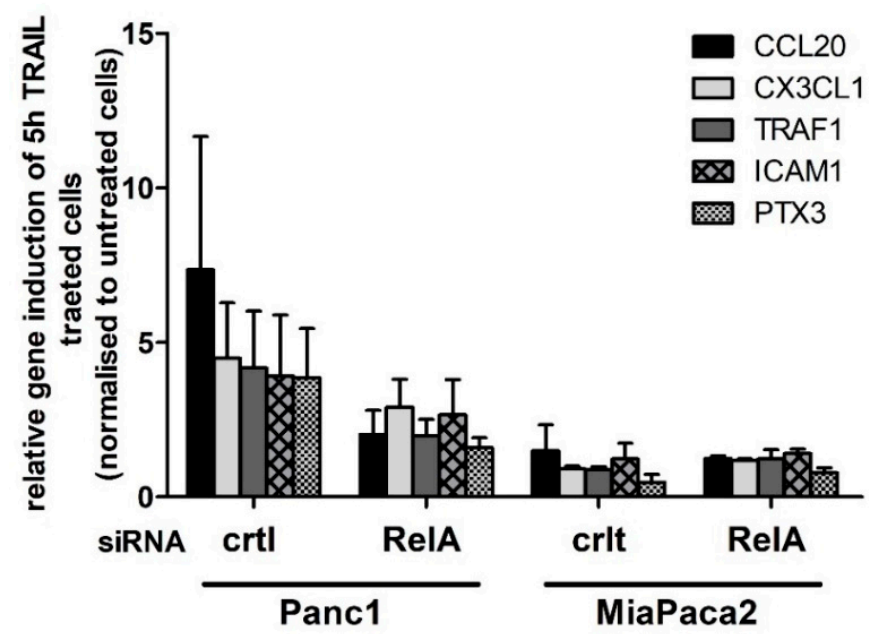

B

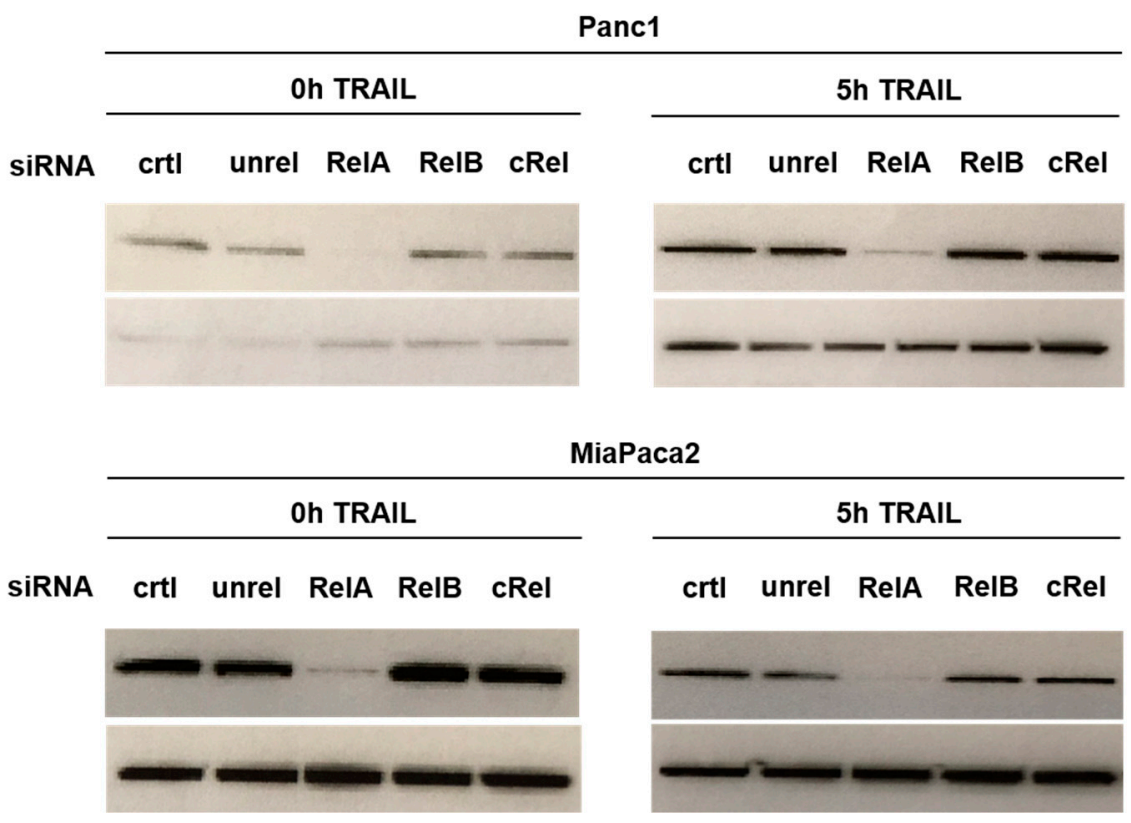

Figure 1. Top 5 upregulated TRAIL responsive genes in resistant PDAC cell lines. PDAC cells were transfected with the indicated siRNAs (unrel: unrelated control siRNA) for $48 \mathrm{~h}$. Subsequent cells were left untreated or treated with $10 \mathrm{ng} / \mathrm{mL}$ TRAIL for $5 \mathrm{~h}$ and a genome wide expression analysis (A) or western blot analysis (B) were performed. (A) Relative gene induction ( $5 \mathrm{~h}$ TRAIL treatment compared to untreated control siRNA cells) of the five strongest upregulated genes of the resistant cell line (Panc1) compared to the sensitive cell line (MiaPaca2) and the effect of transfection of the cells with RelA siRNA is shown. Mean of three independent replicates \pm SD are shown; (B) Western bots whole cell lysates were analyzed using the p65/RelA antibody (upper lane) or Hsp90 antibody (lower lane) as control. One representative out of three is shown. 
The two strongest regulated genes identified by this procedure are two chemokines: CCL20 and CX3CL1. In this study, we will focus on the chemokine CX3CL1, because it is reported to be highly upregulated in PDAC specimens and elevated CX3CL1 expression in PDAC is associated with a poor prognosis in overall survival [21].

In a first step, the results of the transcriptome arrays were verified. Panc1 and MiaPaca2 cells were treated with $10 \mathrm{ng} / \mathrm{mL}$ TRAIL for 3 and $5 \mathrm{~h}$ or were left untreated. As shown in Figure 2A, the CX3CL1 mRNA expression was significantly upregulated after 3 and $5 \mathrm{~h}$ of TRAIL treatment compared to untreated Panc1 cells. By contrast, in TRAIL sensitive MiaPaca2 cells the low basal CX3CL1 expression was almost unaffected by TRAIL treatment.

The knock down of the NF-KB subunit RelA with a specific siRNA led to a reduction of CX3CL1 mRNA expression (Figure 2B) and in accordance with this, both, the basal as well as the TRAIL induced protein expression were clearly reduced in RelA siRNA treated cell supernatants (Figure 2C). The sensitive MiaPaca2 cells expressed CX3CL1 protein below the detection limit of the ELISA. To enable the analysis of the function of CX3CL1 in TRAIL mediated apoptosis resistance in further experiments, the efficacy of two independent CX3CL1 specific siRNAs was confirmed on RNA (Figure 2B) and protein level (Figure 2C) in Panc1 cells.

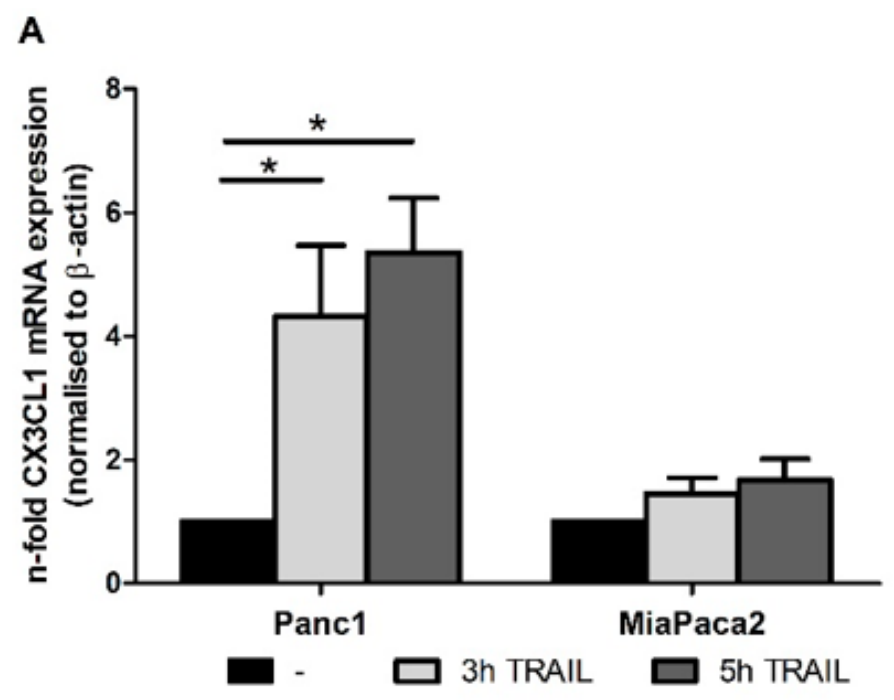

B

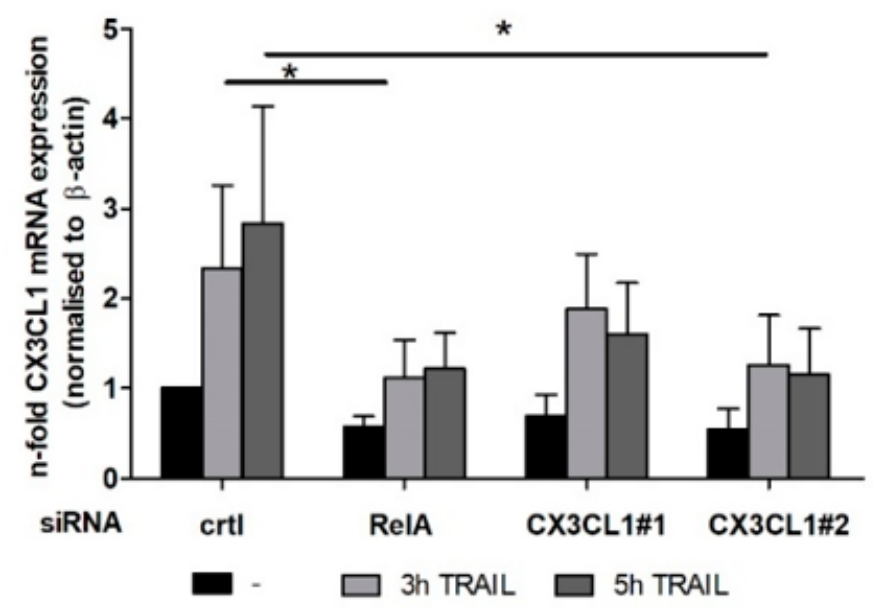

Figure 2. Cont. 


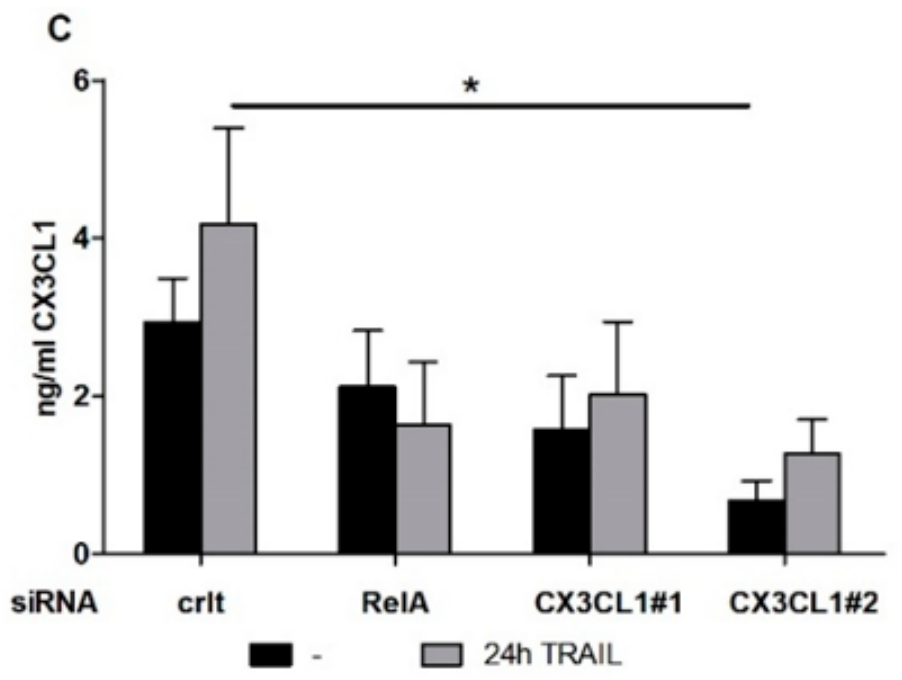

Figure 2. TRAIL upregulates CX3CL1 expression in resistant PDAC in a RelA dependent fashion (A) Panc1 and MiaPaca2 cells or (B) siRNA transfected Panc1 were treated TRAIL (10 ng/mL) for indicated times or left untreated and CX3CL1 mRNA expression was analyzed by realtime PCR. For control, $\beta$-actin qPCR was conducted; (C) Media were chanced to $0.5 \%$ FCS containing media $48 \mathrm{~h}$ after transfection and cells were treated with $10 \mathrm{ng} / \mathrm{mL}$ TRAIL for left untreated. After $24 \mathrm{~h}$ supernatants of Panc1 cells were collected and the concentration of CX3CL1 in the media was determined by ELISA. Data represent mean values \pm SD from four independent experiments performed in duplicates. ${ }^{*} p$-values $<0.05$.

\subsection{RelA Binds to CX3CL1 Promoter after TRAIL Treatment}

The CX3CL1 promoter harbors three putative NF- $\mathrm{kB}$ binding sites (Figure 3A and [22]) but, to our knowledge, none of these has been correlated with TRAIL induced CX3CL1 expression, yet. To show the binding of RelA to the CX3CL1 promoter, nuclear extracts of TRAIL treated or untreated Panc1 cells were subjected to electro mobility shift assays (EMSAs) by using three different oligonucleotides, each containing one of the potential NF- $\mathrm{KB}$ binding site. As shown in Figure 3B, only the first ( -279 to $-272 \mathrm{bp}$ ) and second ( -534 to $-523 \mathrm{bp}$ upstream of the putative transcriptional start site) NF- $\mathrm{KB}$ binding sites show a transient activation ( $3 \mathrm{~h}$ ) after TRAIL treatment (Figure 3B). In supershift experiments, antibodies against RelA, RelB and c-Rel confirmed the presence of a RelA containing NF- $K B$ complex to these two binding sites of the CX3CL1 promoter. By contrast, no binding of RelB or c-Rel containing NF- $\mathrm{kB}$ dimers was detected (Figure 3C).

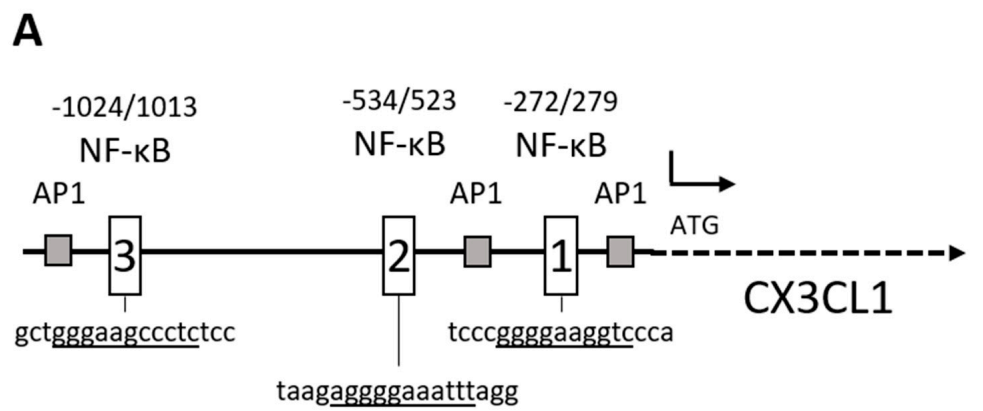

Figure 3. Cont. 


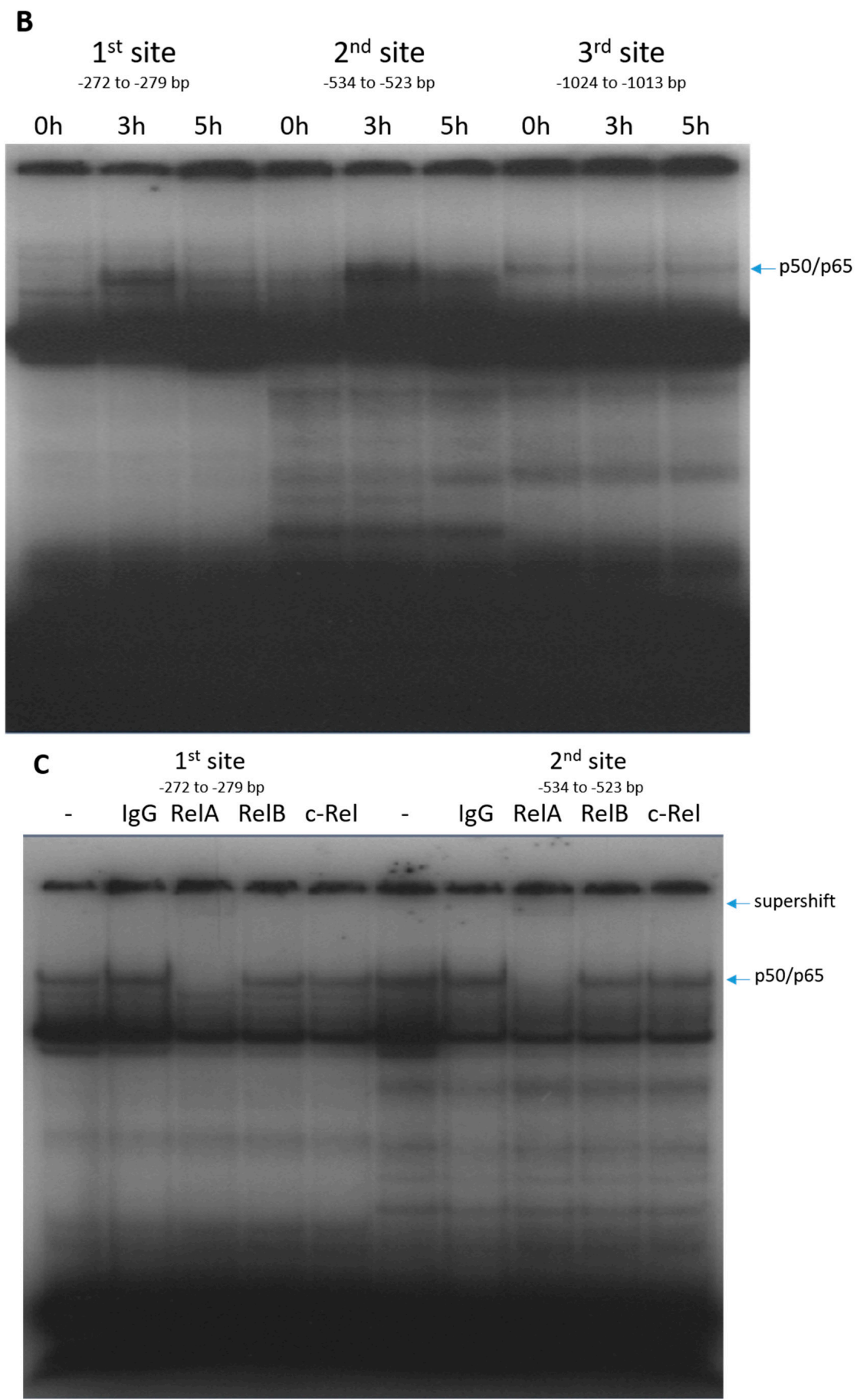

Figure 3. Binding of $\mathrm{p} 50 /$ RelA to putative NF- $\mathrm{kB}$ binding sites of the CX3CL1 promoter. (A) By sequence analysis three recognition motifs for NF- $\mathrm{KB}$ binding were identified in the CX3CL1 promoter. The consensus motif of the DNA sequences in these regions (written below) is underlined; (B) Panc1 cells were left untreated or treated with $10 \mathrm{ng} / \mathrm{mL}$ TRAIL for $3 \mathrm{~h}$ or $5 \mathrm{~h}$, respectively. Nuclear extracts were submitted to EMSA with an oligonucleotide containing the potential NF- $\kappa B$ binding site of the CX3CL1 promoter. One representative out of two independent experiments is shown; (C) Nuclear extracts from $3 \mathrm{~h}$ TRAIL treated Panc1 cells were analyzed in supershift experiments using the indicated antibodies and oligonucleotides containing the potential NF- $\mathrm{B}$ binding site of the CX3CL1 promoter. One representative out of two independent experiments is shown. 


\subsection{CX3CL1 Does Not Induce Direct Apoptosis in Panc1 Cells}

Pancreatic cancer cells make use of cytokines through autocrine-signaling pathways to elevate their own growth, angiogenesis or drug resistance [4]. This associates with an upregulated expression of the CX3CL1 receptor, CX3CR1, in pancreatic cancer specimen [23] and therefore our array analysis prompted us to investigate whether the TRAIL-NF- $\mathrm{KB}$ mediated CX3CL1 expression directly affects the apoptosis resistance of PDAC cells. Panc1 cells were treated with RelA or CX3CL1 specific siRNA, stimulated with TRAIL and analyzed for apoptotic cell death. Both caspase $3 / 7$ assay and counting the subG1 fraction of cells showed no direct impact of CX3CL1 on the TRAIL mediated apoptosis while RelA specific siRNA led to a significant sensitization of the cells towards TRAIL induced apoptosis (Figure 4A,B) without significant effects of any siRNA on the basal apoptosis of untreated cells. Furthermore, we were able to exclude a direct effect of siRNA mediated knockdown of CX3CL1 on proliferation or migration of PDAC cells.

\section{A}

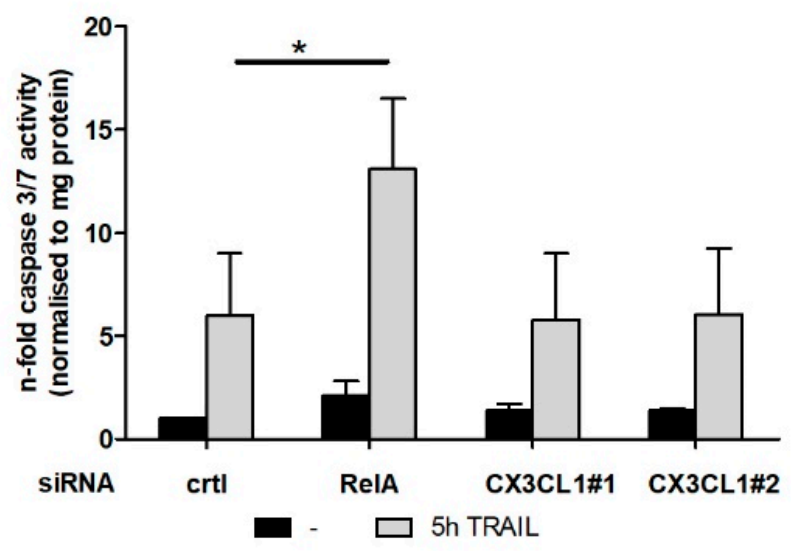

B

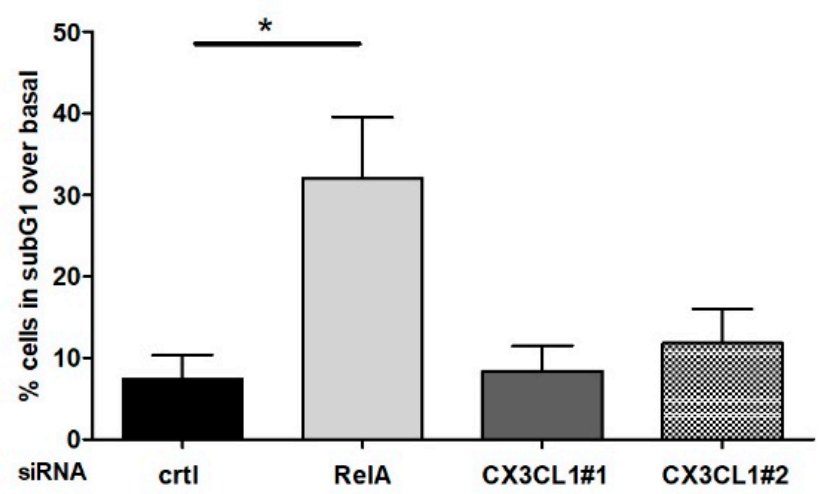

Figure 4. CX3CL1 does not directly affect TRAIL induced apoptosis in PDAC cells. Panc1 cells were subjected to CX3CL1 or RelA siRNA mediated knockdown for $48 \mathrm{~h}$. After TRAIL treatment $(10 \mathrm{ng} / \mathrm{mL})$ apoptosis was measured by analyzing Caspase 3/7-activity $5 \mathrm{~h}$ after TRAIL stimulation (A) or subG1 fragmentation $24 \mathrm{~h}$ after TRAIL stimulation (B). Data of three independent experiments are expressed as n-fold Caspase 3/7-activity or \% of subG1 content. Data represent mean values $\pm \mathrm{SD}$ from three independent experiments performed in duplicates. ${ }^{*} p$-values $<0.05$. 


\subsection{CX3CL1 Enhances the Migration of PBMCs towards PDAC Cells}

The chemokine CX3CL1 acts as chemoattractant for macrophages, monocytes, dendritic cells, T-cells and natural killer cells, that express its receptor CX3CR1 [24,25]. Based on this, we investigated the migration of PBMCs from healthy volunteer donors in Boyden Chamber experiments as a function of the elevated CX3CL1 release in TRAIL treated PDAC cells. In approaches with supernatants from control siRNA transfected and $24 \mathrm{~h}$ TRAIL treated Panc1 cells, there was a significantly induced migration of PBMCs towards the lower compartment compared to supernatants from untreated cells (Figure 5). This enhanced TRAIL mediated migration of PBMCs was significantly reduced by the use of RelA and CX3CL1 specific siRNA, thus pointing to a TRAIL-RelA-CX3CL1 mediated attraction of immune cells.

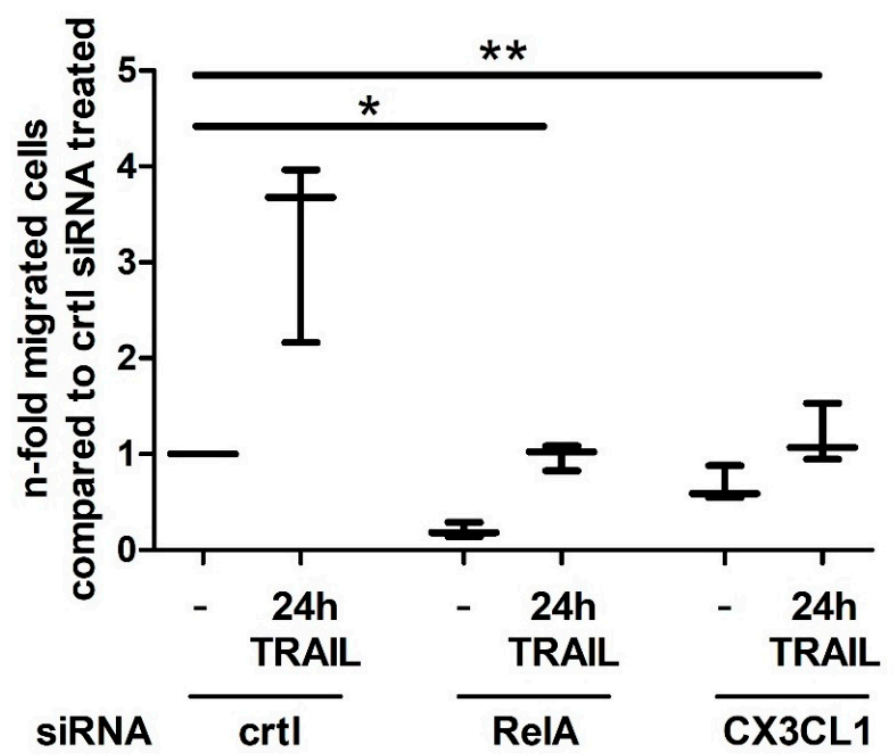

Figure 5. TRAIL induced PBMC migration is RelA and CX3CL1 dependent. PBMCs from healthy donors were isolated and subjected to migration assays. In a transwell system PBMCs were seeded into matrigel coated inserts and migration in dependence of the indicated Panc1 supernatants was measured. Plot from 3 independent measurements show the median (horizontal bar), the whiskers represent the minimum/ maximum data. ${ }^{*} p$-value $<0.025 ;{ }^{* *} p$-value $<0.05$.

\subsection{CX3CL1 Attracted PBMCs Interfere with TRAIL Mediated Apoptosis in Panc1 Cells}

Since we have shown that CX3CL1 has no direct, autocrine effect on PDAC cell apoptosis under TRAIL treatment and observed an enhanced migration of the PBMCs due to elevated CX3CL1 expression, we next analyzed the impact of CX3CL1 attracted immune cells on Panc1 cell apoptosis.

In co-culture experiments, siRNA treated Panc1 cells were cultured with PBMCs, TRAIL treated and subsequently subjected to apoptosis assay. As shown in control siRNA treated cells, the resistance towards TRAIL mediated apoptosis was further enhanced by the co-cultivation with PBMCs (Figure 6). Knocking down the CX3CL1 expression in Panc1 cells by specific siRNA abolished this TRAIL resistance inducing effect by the PBMC co-culture, thus supporting a paracrine role of CX3CL1 in apoptosis resistance of PDAC cells. 


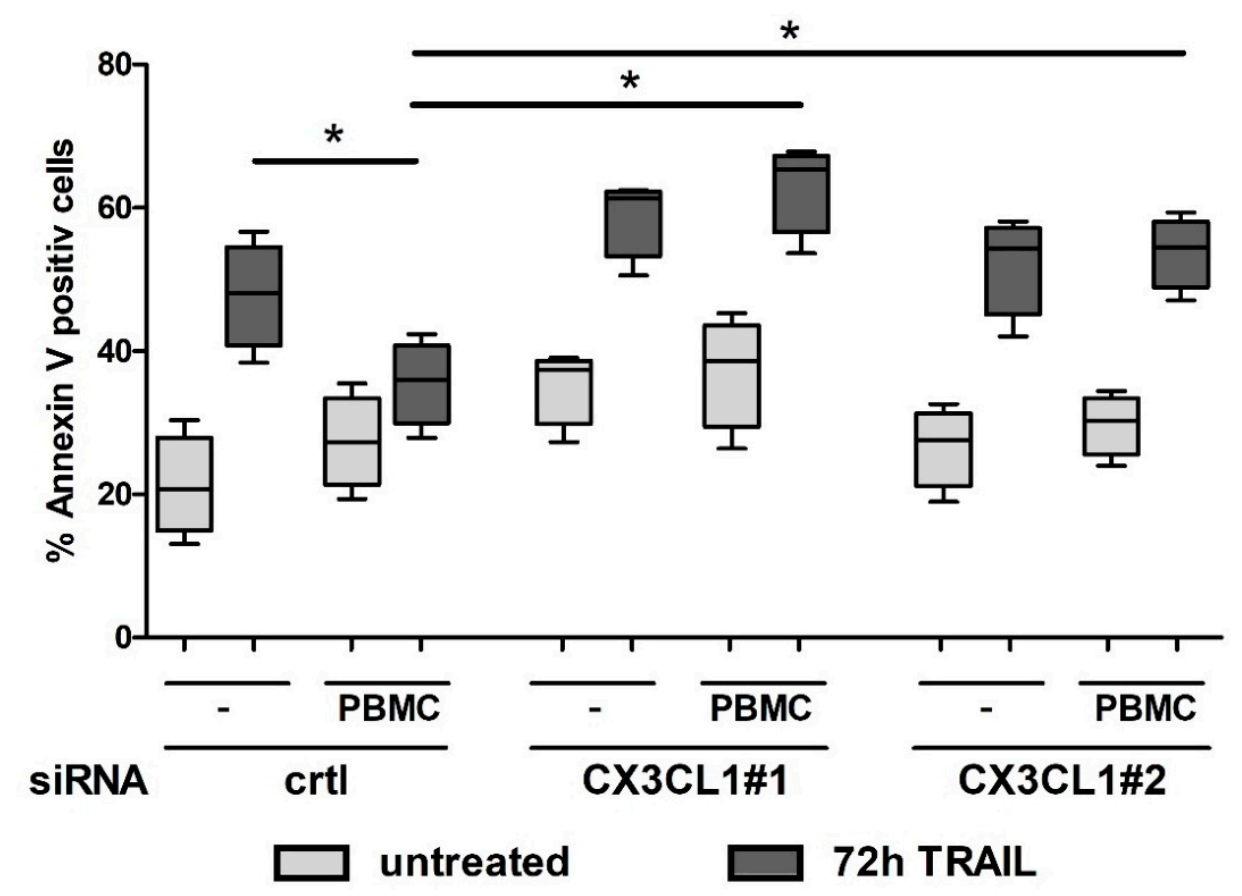

Figure 6. PBMC mediated increase of resistance of PDAC cells towards TRAIL treatment. Panc1 cells were transfected with indicated siRNAs, mono- or co-cultured with PBMCs for $72 \mathrm{~h}$ and treated with or without $10 \mathrm{ng} / \mathrm{mL}$ TRAIL. Co-cultured Panc1 cells were subjected to AnnexinV/PI apoptosis assay. Box plots from 4 independent measurements show the $25 \%$ quantile, the median and $75 \%$ quantile (horizontal bars), the whiskers represent the minimum/maximum data of $\mathrm{n}$-fold AnnexinV positive cells * $p$-values $<0.05$.

\section{Discussion}

To identify NF-кB target genes, especially RelA target genes responsible for resistance towards TRAIL induced apoptosis, a genome wide unbiased approach was applied and identified two chemokines as the most regulated genes: CX3CL1 and CCL20. Combining this result with the fact that chemokines lead to an elevated attraction of immune cells underlines the importance of an interplay of tumor and immune cells in cancer development and progression.

CX3CL1, originally named fractalkine, is a unique member of the forth class of chemokines $(\mathrm{CX} 3 \mathrm{C})$ and interacts with its highly selective chemokine receptor CX3CR1 which is expressed on different lymphocytes (NK-cell, T-cells, dendritic cells, monocytes) [26,27]. In smooth muscle cells, pro-inflammatory cytokines like TNF- $\alpha$ or IFN- $\gamma$ induce CX3CL1 expression [28]. TRAIL resistant pancreatic cancer cell lines show a higher basal and inducible NF- $\kappa B$ activity compared to sensitive cell lines [6,7] and TRAIL treatment induces CX3CL1 expression in these cells. This inducible CX3CL1 expression was traced back to NF- $\mathrm{BB}$ binding to the $-272 / 279$ and $-534 / 523 \mathrm{bp}$ NF- $\mathrm{kB}$ binding sites of the CX3CL1 promoter, as shown by electromobility shift assays. This TRAIL mediated activation of CX3CL1 is driven by a RelA centered NF- $\mathrm{BB}$ signaling pathway, while the other transactivating subunits RelB and c-Rel had no impact on CX3CL1 expression. These results are in line with CX3CL1 promoter analysis in smooth muscle cells where a binding of the NF- $\mathrm{kB}$ subunit RelA to the CX3CL1 promoter during atherogenesis is shown. By luciferase assays, Gan et al. verified a functionally active region within $655 \mathrm{bp}$ upstream of the transcriptional starting point in the CX3CL1 gene, but no further enhancement through an enlargement of the analyzed promoter fragment was observed [22].

CX3CL1 is a transmembrane chemokine expressed either on the cell surface or as a soluble glycoprotein, each mediating different biological activities. While the membrane-anchored CX3CL1 functions as an adhesion molecule fostering the retention of lymphocytes to CX3CL1 expressing endothelial cells the shed soluble form acts as a chemoattractant inducing migration and extravasation 
of lymphocytes into inflamed tissue [29]. In this context, the attraction of splenic lymphocytes by supernatants of CX3CL1 transduced murine hepatocellular carcinoma or neuroblastoma cells was shown $[30,31]$. Conditioned media from IFN- $\gamma$ activated smooth muscle cells also induce a CX3CL1 mediated monocyte chemotaxis towards the increasing chemoattractant signal [22]. Visa versa, the transduced expression of receptor CX3CR1 in T lymphocytes led to an enhanced homing towards CX3CL1 producing tumors [27]. In line with these observations, our results show an augmented migration of PBMCs based on a TRAIL mediated activation of RelA/ NF- $\mathrm{kB}$ and subsequent CX3CL1 expression in pancreatic cancer cells.

Similar to the split function of CX3XL1 are clinical discrepancies reported on the role of CX3CL1/CX3CR1 axis in tumors. On the one hand, the CX3CL1/CX3CR1 signaling transduces antitumor effects going along with a better prognosis for the patient like in hepatocellular, gastric adeno carcinoma [32,33]. Ohta et al. attribute the better prognosis of colorectal cancer patients with high CX3CL1 expression to a recruitment of cytotoxic T-cells and NK cells which for their part mediate tumor cell cytotoxicity using a perforin and granzyme B mechanism [34]. On the other hand, CX3XL1/CX3CR1 signaling axis transduces pro-survival, proliferative and metastatic signals, favoring tumor progression. In breast and prostate cancer a higher expression of CX3CL1 is associated with the occurrence of metastasis $[35,36]$. Human surgical specimen from pancreatic cancer patients revealed a high expression of CX3CL1 compared to control tissue. This elevated CX3CL1 expression could be further attributed to significant shorter overall survival times compared to patients with low CX3CL1 levels [21]. The mechanisms, by which the CX3CL1/CX3CR1 axis affects the pathogenesis and survival of cancer cells, are poorly explored. In epithelial ovarian carcinoma specimen CX3CL1 expression was correlated with positive Ki67 proliferation marker staining and phosphorylation of Akt, whose hyperactivation is related to the control of cell proliferation [37]. The treatment of aortic smooth muscle cells with recombinant CX3CL1 protein promotes cell proliferation and the phosphorylation of Bad, inhibiting its apoptotic activity [28]. In the present study, we could not show a direct impact of CX3CL1 on TRAIL mediated apoptosis but provide instead strong evidence for a paracrine-signaling pathway which might contribute to the described protumorigenic action of CX3CL1 in pancreatic cancer cells. The PBCM-mediated resistance towards TRAIL was shown to be at least in part on a RelA-CX3CL1 paracrine pathway.

To further consolidate the described cancer cell-immune cell interplay as a potential point of action of anti- tumor approaches and to get a better understanding of the diverse functions of CX3CL1 in discrete tumor entities additional analysis have to be done. Nevertheless, our data underscore the relevance of a cancer-immune crosstalk for novel therapeutic interventions.

\section{Materials and Methods}

\subsection{Materials}

Cell culture media, supplements and fetal calf serum (FCS) were purchased from Biochrom (Berlin, Germany), human serum albumin (HSA) from Grifols (Frankfurt, Germany) and Killer-Trail was from Enzo Life Science/Alexis (Lörrach, Germany).

\subsection{Cell Culture}

The human PDAC cell line Panc1 was cultured in RPMI 1640 medium supplemented with 10\% FCS, $1 \%$ L-glutamine and $1 \%$ sodium pyruvate. MiaPaca2 cells were cultured in Dulbecco's Modified Eagle Medium (DMEM, high glucose) supplemented with 10\% FCS, 2.5\% HSA and 1\% L-glutamine. The cells were incubated at $37{ }^{\circ} \mathrm{C}$ with $5 \% \mathrm{CO}_{2}$ at $85 \%$ humidity. Both cell lines were obtained from Deutsche Sammlung von Mikroorganismen und Zellkulturen (DSMZ), Braunschweig. 


\subsection{RNA Preparation and Realtime PCR}

Total-RNA preparation was performed by using RNAeasy Kit (Qiagen, Hilden, Germany) following the manufacturer's instructions and $500 \mathrm{ng}$ of RNA were applied to Reverse Transcription (Thermo Scientific, Whaltham, MA, USA). Realtime PCR was done by using QuantiNova SYBR Green PCR Kit (Qiagen) and a final concentration of $0.3 \mathrm{nM}$ gene specific primer. Primers for mRNA expression were purchased from Eurofins Genomics (Ebersberg, Germany):

CX3CL1-F: 5'-CACCACGGTGTGACGAAATG -3'; CX3CL1-R: 5'-TCTCCAAGATGATTGCGCGT3'; $\beta$-actin-F: 5'-CTCTTCCAGCCTTCCTTCCT-3'; $\beta$-actin-R: 5'-AGCACTGTGTTGGCGTACAG-3'

\section{4. siRNA Transfection}

Panc1 cells were submitted to lipofection. In detail, cells were seeded in 12 well plates and transfection was done using $40 \mathrm{pMol}$ control, RelA or CX3CL1 siRNA mixed with $12 \mu \mathrm{L}$ HiPerFect transfection reagent (Qiagen). For each gene target at least two different siRNAs were used: RelA: s11915, s11916; RelB: si11917; cRel si11905; CX3CL1: s12630; s12631 (Thermo Scientific).

\subsection{Gel Shift Assays}

Preparation of nuclear extracts and gel shift assays were done as described previously [7]. For the detection of NF-KB binding to the CX3CL1 promoter three different $\gamma^{32}$-P-labeled oligonucleotides (CX3CL1-NF-кB-1: 5'-CCAGCCTCCCGGGGAAGGTCCCAGTATGAC-3'; CX3CL1-NF-кB-2: 5' GATTCTAAGAGGGGAAATTTAGGGGTCCAT; CX3CL1-NF-кB-3: 5'-GGCCGGTGCTGGGAAGCCCTC TCCCCATTG (MWG Eurofins) harboring an already described NF- $\kappa B$ recognition site (underlined) [22] were used. Supershift experiments were performed by inserting $4 \mu \mathrm{g}$ of RelA, RelB or cRel antibody into the preparation (all Santa Cruz Biotechnology, Heidelberg, Germany).

\subsection{Genome Wide Transcriptome Profiling and Cluster Analysis}

All transcriptome data were collected and analyzed as described [6]. Processing was done according to MIAME standards and made publicly available by submitting to NCBI GEO (series accession: GSE87287; http:/ / www.ncbi.nlm.nih.gov/geo / query / acc.cgi?acc=GSE87287).

\subsection{PBMC Isolation}

Isolation of PBMCs from healthy adult blood donors was performed as described before [6]. Isolated PBMCs were cultured in RPMI 1640 media containing $1 \%$ penicillin/streptomycin, $1 \%$ L-glutamine and $0.5 \%$ HSA.

\subsection{Migration Assay}

For analyzing the migration of PBMCs transwell inserts $(5.0 \mu \mathrm{m}$ pore size; 24 well, Costar, NY, USA) were coated with $100 \mu \mathrm{L}$ of Matrigel (growth factor reduced, BD Bioscience, Heidelberg, Germany) diluted 1:5 with RPMI 1640 supplemented with 0.5\% HSA, 1\% L-glutamine, $1 \%$ penicillin/streptomycin. After coagulation $500 \mu \mathrm{L}$ of conditioned supernatants were given into the wells of the plate and 50.000 PBMCs were seeded into each transwell. After $24 \mathrm{~h}$ inserts were discarded, supernatants were collected and migrated cells were counted by flow cytometry (BD-Facs Verse, BD-Bioscience, Heidelberg, Germany).

\subsection{Co-Culture Assay}

Previous to co-culture assay 30.000 PDAC cells were seeded into 24 well plates and transfected with the indicated siRNAs specified above. After $20 \mathrm{~h}$ media were replaced by $500 \mu \mathrm{L}$ of $\mathrm{x}$-Vivo15 cell culture media (Lonza, Cologne, Germany) $\pm 10 \mathrm{ng} / \mathrm{mL}$ TRAIL. To guarantee the observed effects, based exclusively on paracrine signaling, cell culture inserts with a pore size of $0.4 \mu \mathrm{m}$ (Greiner bio-one, 
Frickenhausen, Germany) were clipped in and 60.000 PBMCs were seeded into these inserts. Following $72 \mathrm{~h}$ of incubation at $37^{\circ} \mathrm{C}$, the PDAC cells were subjected to Annexin V/PI Assay.

\subsection{ELISA}

Panc1 cells were cultured as described above. Before stimulating the cells with $10 \mathrm{ng} / \mathrm{mL}$ TRAIL for $24 \mathrm{~h}$, cell medium were substituted by RPMI 1640 supplemented with $1 \%$ L-glutamine and $1 \%$ sodium pyruvate. The culture supernatants were collected and centrifuged for $5 \mathrm{~min}$ at $1200 \mathrm{rpm}$ and $4{ }^{\circ} \mathrm{C}$. The cell free supernatants were aliquoted and frozen at $-80^{\circ} \mathrm{C}$. Human CX3CL1 Quantikine ELISA from R\&D (Wiesbaden, Germany) was done following the manufacturer's instructions.

\subsection{Western Blotting}

For total cell lysate preparation cells were washed with PBS twice and harvested in lysis buffer (0.125 M Tris; $0.1 \%$ SDS, protease inhibitor cocktail). Gel electrophoresis and immuno-blotting were performed as already described [6] using RelA and HSP90 antibodies (both Santa Cruz Biotechnology).

\subsection{Annexin V/PI Assay}

Cells were trypsinized, washed with PBS and submitted to Annexin V-FITC Kit due to the manufacturer's instructions (Miltenyi Bioscience, Bergisch Gladbach, Germany). Flow cytometry was carried out on a FACS Verse flow cytometer (BD Bioscience) and cells positive for Annexin V were regarded as being apoptotic.

\subsection{Caspase-3/-7 Assay}

Apoptosis induced by Killer-TRAIL was determined by the measurement of Caspase-3/-7 activity (Promega, Mannheim, Germany) according to the manufacturer's instructions and as described [6]. All assays were done in duplicates. Caspase-3/-7 activity was normalized to the protein content of the analyzed cell lysates.

\subsection{Statistics}

Data represent the mean \pm standard deviation and were analyzed by student's $t$-test, $p$-values $<0.05$ were considered as statistically significant and indicated by *

Author Contributions: Conceptualization, C.G., H.S. and A.A.; Methodology, C.G. and F.G.; Validation, C.G., W.E. and F.G.; Formal Analysis, A.A. and S.S.; Investigation, C.G. and F.G.; Resources, S.S.; Data Curation, S.S.; Writing-Original Draft Preparation, C.G.; Writing—Review \& Editing, A.A., H.S., G.S. and S.S.; Visualization, C.G. and A.A.; Supervision, A.A.; Project Administration, S.S.; Funding Acquisition, A.A. and G.S.

Funding: This research was funded by the Sander foundation (2010.076.1) and DFG (AR 381/5-1 and SCHN 959/2-1) and the German Cluster of Excellence "Inflammation at Interfaces".

Acknowledgments: Funding by the Sander foundation (2010.076.1), DFG (AR 381/5-1 and SCHN 959/2-1) and the German Cluster of Excellence "Inflammation at Interfaces" is acknowledged.

Conflicts of Interest: The authors declare no conflict of interest.

\section{Abbreviations}

PDAC pancreatic ductal adenocarcinoma

TRAIL TNF alpha related apoptosis inducing ligand

NF-кB nuclear factor kappa-light-chain-enhancer of

activated $\mathrm{B}$ cells

CX3CL1 chemokine (C-X3-C motif) ligand 1

CX3CR1 CX3C chemokine receptor 1

RelA nuclear factor NF-kappa-B p65 subunit 


\section{References}

1. Siegel, R.L.; Miller, K.D.; Jemal, A. Cancer statistics, 2018. CA Cancer J. Clin. 2018, 68, 7-30. [CrossRef] [PubMed]

2. Neesse, A.; Algul, H.; Tuveson, D.A.; Gress, T.M. Stromal biology and therapy in pancreatic cancer: A changing paradigm. Gut 2015, 64, 1476-1484. [CrossRef] [PubMed]

3. Van Audenaerde, J.R.M.; Roeyen, G.; Darcy, P.K.; Kershaw, M.H.; Peeters, M.; Smits, E.L.J. Natural killer cells and their therapeutic role in pancreatic cancer: A systematic review. Pharmacol. Ther. 2018, in press. [CrossRef] [PubMed]

4. Liou, G.Y. Inflammatory Cytokine Signaling during Development of Pancreatic and Prostate Cancers. J. Immunol. Res. 2017, 2017, 7979637. [CrossRef] [PubMed]

5. Liou, G.Y.; Bastea, L.; Fleming, A.; Doppler, H.; Edenfield, B.H.; Dawson, D.W.; Zhang, L.; Bardeesy, N.; Storz, P. The Presence of Interleukin-13 at Pancreatic ADM/PanIN Lesions Alters Macrophage Populations and Mediates Pancreatic Tumorigenesis. Cell Rep. 2017, 19, 1322-1333. [CrossRef] [PubMed]

6. Geismann, C.; Grohmann, F.; Dreher, A.; Hasler, R.; Rosenstiel, P.; Legler, K.; Hauser, C.; Egberts, J.H.; Sipos, B.; Schreiber, S.; et al. Role of CCL20 mediated immune cell recruitment in NF-kappaB mediated TRAIL resistance of pancreatic cancer. Biochim. Biophys. Acta 2017, 1864, 782-796. [CrossRef] [PubMed]

7. Geismann, C.; Grohmann, F.; Sebens, S.; Wirths, G.; Dreher, A.; Hasler, R.; Rosenstiel, P.; Hauser, C.; Egberts, J.H.; Trauzold, A.; et al. c-Rel is a critical mediator of NF-kappaB-dependent TRAIL resistance of pancreatic cancer cells. Cell Death Dis. 2014, 5, e1455. [CrossRef] [PubMed]

8. Arlt, A.; Muerkoster, S.S.; Schafer, H. Targeting apoptosis pathways in pancreatic cancer. Cancer Lett. 2013, 332, 346-358. [CrossRef] [PubMed]

9. Wicker, C.A.; Sahu, R.P.; Kulkarni-Datar, K.; Srivastava, S.K.; Brown, T.L. BITC Sensitizes Pancreatic Adenocarcinomas to TRAIL-induced Apoptosis. Cancer Growth Metastasis 2010, 2009, 45-55. [CrossRef] [PubMed]

10. Kretz, A.L.; von Karstedt, S.; Hillenbrand, A.; Henne-Bruns, D.; Knippschild, U.; Trauzold, A.; Lemke, J. Should We Keep Walking along the Trail for Pancreatic Cancer Treatment? Revisiting TNF-Related Apoptosis-Inducing Ligand for Anticancer Therapy. Cancers 2018, 10, 77. [CrossRef] [PubMed]

11. Geismann, C.; Arlt, A.; Sebens, S.; Schafer, H. Cytoprotection "gone astray": Nrf2 and its role in cancer. Onco Targets Ther. 2014, 7, 1497-1518. [PubMed]

12. Zwacka, R.M.; Stark, L.; Dunlop, M.G. NF-kappaB kinetics predetermine TNF-alpha sensitivity of colorectal cancer cells. J. Gene Med. 2000, 2, 334-343. [CrossRef]

13. Perkins, N.D. The diverse and complex roles of NF-kappaB subunits in cancer. Nat. Rev. Cancer 2012, 12, 121-132. [CrossRef] [PubMed]

14. Arlt, A.; Schafer, H.; Kalthoff, H. The 'N-factors' in pancreatic cancer: Functional relevance of NF-kappaB, NFAT and Nrf2 in pancreatic cancer. Oncogenesis 2012, 1, e35. [CrossRef] [PubMed]

15. Plantivaux, A.; Szegezdi, E.; Samali, A.; Egan, L. Is there a role for nuclear factor kappaB in tumor necrosis factor-related apoptosis-inducing ligand resistance? Ann. N. Y. Acad. Sci. 2009, 1171, 38-49. [CrossRef] [PubMed]

16. Thomas, R.P.; Farrow, B.J.; Kim, S.; May, M.J.; Hellmich, M.R.; Evers, B.M. Selective targeting of the nuclear factor-kappaB pathway enhances tumor necrosis factor-related apoptosis-inducing ligand-mediated pancreatic cancer cell death. Surgery 2002, 132, 127-134. [CrossRef] [PubMed]

17. Zhou, D.H.; Trauzold, A.; Roder, C.; Pan, G.; Zheng, C.; Kalthoff, H. The potential molecular mechanism of overexpression of uPA, IL-8, MMP-7 and MMP-9 induced by TRAIL in pancreatic cancer cell. Hepatobiliary Pancreat Dis. Int. 2008, 7, 201-209. [PubMed]

18. Greten, F.R.; Weber, C.K.; Greten, T.F.; Schneider, G.; Wagner, M.; Adler, G.; Schmid, R.M. Stat3 and NF-kappaB activation prevents apoptosis in pancreatic carcinogenesis. Gastroenterology 2002, 123, 2052-2063. [CrossRef] [PubMed]

19. Kong, R.; Sun, B.; Jiang, H.; Pan, S.; Chen, H.; Wang, S.; Krissansen, G.W.; Sun, X. Downregulation of nuclear factor-kappaB p65 subunit by small interfering RNA synergizes with gemcitabine to inhibit the growth of pancreatic cancer. Cancer Lett. 2010, 291, 90-98. [CrossRef] [PubMed] 
20. Arlt, A.; Gehrz, A.; Muerkoster, S.; Vorndamm, J.; Kruse, M.L.; Folsch, U.R.; Schafer, H. Role of NF-kappaB and $\mathrm{Akt} / \mathrm{PI} \mathrm{K}$ in the resistance of pancreatic carcinoma cell lines against gemcitabine-induced cell death. Oncogene 2003, 22, 3243-3251. [CrossRef] [PubMed]

21. Xu, X.; Wang, Y.; Chen, J.; Ma, H.; Shao, Z.; Chen, H.; Jin, G. High expression of CX3CL1/CX3CR1 axis predicts a poor prognosis of pancreatic ductal adenocarcinoma. J. Gastrointest. Surg. 2012, 16, 1493-1498. [CrossRef] [PubMed]

22. Gan, A.M.; Butoi, E.; Manea, A.; Pirvulescu, M.M.; Stan, D.; Simion, V.; Calin, M.; Simionescu, M.; Manduteanu, I. Functional analysis of the fractalkine gene promoter in human aortic smooth muscle cells exposed to proinflammatory conditions. FEBS J. 2014, 281, 3869-3881. [CrossRef] [PubMed]

23. Marchesi, F.; Piemonti, L.; Fedele, G.; Destro, A.; Roncalli, M.; Albarello, L.; Doglioni, C.; Anselmo, A.; Doni, A.; Bianchi, P.; et al. The chemokine receptor CX3CR1 is involved in the neural tropism and malignant behavior of pancreatic ductal adenocarcinoma. Cancer Res. 2008, 68, 9060-9069. [CrossRef] [PubMed]

24. Lee, M.; Lee, Y.; Song, J.; Lee, J.; Chang, S.Y. Tissue-specific Role of CX3CR1 Expressing Immune Cells and Their Relationships with Human Disease. Immune Netw. 2018, 18, e5. [CrossRef] [PubMed]

25. Imai, T.; Yasuda, N. Therapeutic intervention of inflammatory/immune diseases by inhibition of the fractalkine (CX3CL1)-CX3CR1 pathway. Inflamm. Regen. 2016, 36, 9. [CrossRef] [PubMed]

26. Jones, B.A.; Beamer, M.; Ahmed, S. Fractalkine/CX3CL1: A potential new target for inflammatory diseases. Mol. Interv. 2010, 10, 263-270. [CrossRef] [PubMed]

27. Siddiqui, I.; Erreni, M.; van Brakel, M.; Debets, R.; Allavena, P. Enhanced recruitment of genetically modified CX3CR1-positive human T cells into Fractalkine/CX3CL1 expressing tumors: Importance of the chemokine gradient. J. Immunother. Cancer 2016, 4, 21. [CrossRef] [PubMed]

28. Chandrasekar, B.; Mummidi, S.; Perla, R.P.; Bysani, S.; Dulin, N.O.; Liu, F.; Melby, P.C. Fractalkine (CX3CL1) stimulated by nuclear factor kappaB (NF-kappaB)-dependent inflammatory signals induces aortic smooth muscle cell proliferation through an autocrine pathway. Biochem. J. 2003, 373, 547-558. [CrossRef] [PubMed]

29. Ferretti, E.; Pistoia, V.; Corcione, A. Role of fractalkine/CX3CL1 and its receptor in the pathogenesis of inflammatory and malignant diseases with emphasis on B cell malignancies. Mediat. Inflamm. 2014, 2014, 480941. [CrossRef] [PubMed]

30. Tang, L.; Hu, H.D.; Hu, P.; Lan, Y.H.; Peng, M.L.; Chen, M.; Ren, H. Gene therapy with CX3CL1/Fractalkine induces antitumor immunity to regress effectively mouse hepatocellular carcinoma. Gene Ther. 2007, 14, 1226-1234. [CrossRef] [PubMed]

31. Zeng, Y.; Huebener, N.; Fest, S.; Weixler, S.; Schroeder, U.; Gaedicke, G.; Xiang, R.; Schramm, A.; Eggert, A.; Reisfeld, R.A.; et al. Fractalkine (CX3CL1)- and interleukin-2-enriched neuroblastoma microenvironment induces eradication of metastases mediated by T cells and natural killer cells. Cancer Res. 2007, 67, 2331-2338. [CrossRef] [PubMed]

32. Matsubara, T.; Ono, T.; Yamanoi, A.; Tachibana, M.; Nagasue, N. Fractalkine-CX3CR1 axis regulates tumor cell cycle and deteriorates prognosis after radical resection for hepatocellular carcinoma. J. Surg. Oncol. 2007, 95, 241-249. [CrossRef] [PubMed]

33. Hyakudomi, M.; Matsubara, T.; Hyakudomi, R.; Yamamoto, T.; Kinugasa, S.; Yamanoi, A.; Maruyama, R.; Tanaka, T. Increased expression of fractalkine is correlated with a better prognosis and an increased number of both CD8+ T cells and natural killer cells in gastric adenocarcinoma. Ann. Surg. Oncol. 2008, 15, 1775-1782. [CrossRef] [PubMed]

34. Ohta, M.; Tanaka, F.; Yamaguchi, H.; Sadanaga, N.; Inoue, H.; Mori, M. The high expression of Fractalkine results in a better prognosis for colorectal cancer patients. Int. J. Oncol. 2005, 26, 41-47. [CrossRef] [PubMed]

35. Andre, F.; Cabioglu, N.; Assi, H.; Sabourin, J.C.; Delaloge, S.; Sahin, A.; Broglio, K.; Spano, J.P.; Combadiere, C.; Bucana, C.; et al. Expression of chemokine receptors predicts the site of metastatic relapse in patients with axillary node positive primary breast cancer. Ann. Oncol. 2006, 17, 945-951. [CrossRef] [PubMed] 
36. Tsang, J.Y.; Ni, Y.B.; Chan, S.K.; Shao, M.M.; Kwok, Y.K.; Chan, K.W.; Tan, P.H.; Tse, G.M. CX3CL1 expression is associated with poor outcome in breast cancer patients. Breast Cancer Res. Treat. 2013, 140, 495-504. [CrossRef] [PubMed]

37. Gaudin, F.; Nasreddine, S.; Donnadieu, A.C.; Emilie, D.; Combadiere, C.; Prevot, S.; Machelon, V.; Balabanian, K. Identification of the chemokine CX3CL1 as a new regulator of malignant cell proliferation in epithelial ovarian cancer. PLoS ONE 2011, 6, e21546. [CrossRef] [PubMed] 